Derecho y Realidad

Vol.14 - Núm. 28・ julio - diciembre de 2016

Págs. 245 - 271·ISSN:1692-3936

\title{
Los derechos humanos como límite al sistema carcelario en Colombia
}

\author{
Human Rights as a Limit to the Prison System \\ in Colombia
}

Gloria Cecilia Palacios Guastar*

\section{Resumen}

Al analizar el sistema penitenciario en general, como asignatura adscrita a las ciencias penales y criminológicas, se presenta una constante discusión basada en los derechos humanos, como enfoque de una estructuración teórica y práctica del ideal de un sistema carcelario.Así, cuando se aborda un sistema orientado al castigo o sanción por una conducta determinada, es necesario tener en cuenta la conclusión actual de la evolución doctrinal y normativa de los derechos humanos al respecto, que provee un límite universal y deontológicamente aplicable a toda sanción que requiera una reclusión, pero

Fecha de recepción: 07 de julio de 2016.

Fecha de aprobación: 22de agosto de 2016.

\footnotetext{
* Abogada egresada de la Universidad INCCA de Colombia, especialista en Derecho Administrativo de la Universidad Santo Tomás, seccional Bogotá, especialista en Pedagogía para los Derechos Humanos de la Universidad Pedagógica y Tecnológica de Colombia seccional Duitama, y magíster (c) en Derechos Humanos de la Universidad Pedagógica y Tecnológica de Colombia, seccional Tunja.gpalacios21@gmail.com.
} 
que para nuestro enfoque observa con detenimiento el caso colombiano, pues son bien conocidas las especiales condiciones de vulnerabilidad de derechos que imperan en prácticamente todas las prisiones del país.

Por lo tanto, esta investigación expone aquel límite, como resultado de la evolución normativa y doctrinal de los derechos humanos, al que hoy en día se encuentra sometido todo sistema carcelario, con el fin de presentar una guía de entrada para un deber ser en la aplicación de los derechos humanos en el sistema penitenciario en Colombia.

Palabras clave: derechos humanos, sistema penitenciario, sistema carcelario en Colombia, límite al sistema penitenciario, relación entre sistema carcelario y derechos humanos.

\section{Abstract}

lyzing prison system in general, as a subject of Penal and Criminological Sciences, there is a constant discussion based on human rights, as a theoretical and practical structuring of the ideal of a prison system approach. Thus, speaking of a system focused on punishment for a certain behavior, it is necessary to take into account the current conclusion of the doctrinal and normative evolution of human rights in this regard, which above all, provides a limit universal and deontologically applicable to all sanction requiring a detention, but that for our approach it observes carefully the case of Colombia, as the special conditions of vulnerability of rights prevailing in almost all prisons in the country are well known.

Therefore, this research shows that limit, as a result of normative and doctrinal evolution of human rights, which nowadays reigns in the whole prison system, in order to submit an entry guide for a duty to be in the application of human rights in the prison system in Colombia.

Keywords: human rights, prison system in Colombia, limit to the prison system, relationship between prison system and human rights. 


\section{Introducción}

Según la Real Academia de la Lengua Española (2014), la palabra prisión, proveniente del latín prehensio, define la acción de prender, retener y sujetar cosas, denota la privación de la libertad, incluso, el lugar donde se encierra y asegura a los prisioneros.

Así pues, al hablar de prisión, también nos referimos a castigo, sanción y retribución a una conducta generalmente establecida en los códigos penales ${ }^{1}$, donde por supuesto, existen otros mecanismos sancionatorios ${ }^{2}$, pero como dice Zambrano Salazar (2013), la institución carcelaria constituye el mecanismo punitivo más representativo.

En ese orden de ideas, el contemplar el establecimiento penitenciario como la insignia de la retribución punitiva, implica tener en cuenta que la simple restricción de la libertad es una vulneración directa a un derecho de estirpe constitucional ${ }^{3}$, pero que, bajo la óptica del derecho penal, constituye una excepción a los principios rectores del Estado, a causa de una lesión o puesta en peligro injustificada de un bien jurídicamente tutelado.

No obstante la existencia de un fundamento para abstenerse de respetar garantías relacionadas con los derechos humanos ${ }^{4}$, es claro que el poder punitivo estatal no puede tener un alcance desmesurado o ilimitado, pues por el contrario, tiene un límite de coerción, establecido, delineado y plenamente identificado por parte del derecho de los derechos humanos.

De manera que esta frontera para tener en cuenta por parte del sistema carcelario es precisamente la que se entrará a dilucidar con claridad en páginas posteriores, pero para cuyo análisis y entendimiento se requiere de un estudio previo; razón por la cual, empezaremos por analizar el fundamento de los derechos humanos, a fin de conocer el tope de aquel límite, para luego aproximarnos a una definición del derecho penitenciario que nos permita exaltar la relación que tiene con los derechos humanos y poder finalizar con la exposición del objeto central de esta investigación.

1 Para el particular, el eje sustancial del derecho penal colombiano se rige por la Ley 599 del 2000 -Código Penal-; y, el eje formal, por la Ley 906 del 2004 -Código de Procedimiento Penal-.

2 El artículo 34 del Código Penal define las clases de penas, así: principales (privativa de la libertad de prisión, pecuniaria de multa y demás privativas de otros derechos), sustitutivas (prisión domiciliaria como sustitutiva de prisión y arresto de fin de semana, convertible en arresto ininterrumpido como sustitutivo de la multa) y accesorias (son aquellas privativas de otros derechos, como la inhabilitación para el ejercicio de derechos y funciones públicas).

3 Véase artículo 28 de la Constitución Política de Colombia.

4 Pues recuérdese, el artículo 9 de la Declaración Universal de los Derechos Humanos impone que nadie podrá ser arbitrariamente detenido, preso ni desterrado. 


\section{Método}

Se trata de una investigación básica jurídica, dado que el objeto de estudio es constituido por la norma jurídica. Para tal fin, fueron utilizados los métodos descriptivo y retrospectivo de investigación. El primero, debido a que se busca describir el límite proveído por los derechos humanos al sistema penitenciario colombiano; y el segundo, en razón a que se mostrarán los antecedentes legales de este límite, a través de aproximaciones al fundamento de los derechos humanos y del derecho penitenciario y su tratamiento a partir de la doctrina y la normatividad vigentes.

Se combinan fuentes secundarias y terciarias. A partir de las secundarias se analizó ley y doctrina principalmente, en relación con la problemática de estudio y los subtemas que de allí emanaron. En cuanto a las fuentes terciarias, se estudiaron las fuentes de las que hicieron uso otros autores.

El problema de investigación es el siguiente: ¿Cuál es el límite que proveen los derechos humanos al sistema carcelario en Colombia?

Para resolver esta pregunta, se planteó como objetivo general determinar cuál es el límite que proveen los derechos humanos al sistema carcelario en Colombia.

Así, la investigación cuenta con tres aspectos de trascendental importancia: por una parte, el análisis del fundamento de los derechos humanos, para establecer una línea de entrada para plantear el límite ya mencionado; en segundo lugar, el estudio del derecho penitenciario sobre el cual recaería aquel límite; y por último, el análisis de la relación existente entre los derechos humanos y el sistema carcelario, todo lo que llevaría a exponer los derechos humanos como límite al sistema carcelario en Colombia.

Por lo expuesto, los objetivos específicos de esta investigación fueron los siguientes: i) determinar cuál es el fundamento de los derechos humanos, b) establecer una aproximación al derecho penitenciario, c) precisar la relación existente entre los derechos humanos y el sistema carcelario, y d) determinar los derechos humanos como un límite al sistema carcelario en Colombia.

\section{Aproximaciones al fundamento de los derechos humanos}

Establecido el esquema que habrá de regir los capítulos siguientes y teniendo en cuenta las claras limitaciones en la extensión de este trabajo, empezaremos por definir de forma rápida el concepto de los derechos humanos. 


\subsection{Concepto}

Con el pasar del tiempo se ha logrado la comprensión de que todos somos sujetos de una serie de derechos que deben ser protegidos por los gobiernos, respetados y promovidos por toda persona y vivenciados en la práctica cotidiana de manera individual y colectiva.

Esto ha llevado a la comunidad humana a ubicarse en el consenso de que los derechos humanos ${ }^{5}$ son algo tan natural, tan propio del género humano, que siempre han existido y que históricamente se han ido configurando en luchas reivindicativas tanto prácticas como conceptuales.

Así, esta inherencia de los derechos humanos va surgiendo con el clamor de su reconocimiento, al estar menoscabados o disminuidos en regímenes autoritarios de Estados absolutos, cuya noción se va construyendo como las "reivindicaciones de unos bienes primarios considerados de vital importancia para todo ser humano que concretan en cada época histórica las demandas de libertad y de dignidad humana" (Papacchini, 1994, p. 22).

La evolución de este concepto ha forjado un patrimonio de vital importancia para sus titulares, a los que no se está dispuesto a renunciar por ningún motivo, pues ello significaría abandonar la condición humana, los derechos y libertades básicas, el reconocimiento, el respeto y la valoración de ser persona con sus características y condiciones particulares, por el solo hecho de ser persona.

De ahí que la democracia, como instrumento de respeto y libertad bajo el parámetro responsabilidad, basada en el Estado de derecho, sea en última instancia un elemento para lograr la paz y la seguridad internacional, el progreso y el desarrollo económico y social, y el respeto de los derechos humanos;

Entonces y a modo de razonamiento, los derechos humanos, como derechos subjetivos públicos frente al Estado y no como "meros ideales políticos de convivencia", son la consecuencia del pasado mismo de nuestra especie, aquella lucha por un ideal de dignidad humana que, aunque no se encontraba claro, se percibía que todo ser humano, por el simple hecho de nacer y dar la primera bocanada de oxígeno, tenía el derecho de ser libre y decidir su destino.

5 Se usará la abreviatura para derechos humanos, teniendo en cuenta que esta sigla se refiere, hoy en día, más a la Declaración Universal de los Derechos Humanos en forma posterior a la Segunda Guerra Mundial, y no a las definiciones previas. Sin embargo, atendiendo al uso cotidiano que se da a la frase "derechos humanos", se ha decidido utilizar esa simplificación. De todos modos, términos como los derechos, derechos humanos, derechos universales, derechos fundamentales, se usarán en el texto con referencia a DDHH, salvo que sea necesaria alguna aclaración, caso en el que se indicará en nota al pie de página. 
En tal forma podría entrar a discutirse si estos derechos han sido algún tipo de obsequio, siendo lo cierto que se trata de un producto de innumerables luchas que el hombre ha propiciado por independizarse del yugo de la opresión. Por eso es importante reflexionar que no es un simple discurso ideológico el reconocimiento y respeto sobre el concepto de derechos humanos.

Esto ha llevado a que en una sociedad globalizada como la nuestra, se evidencie una mayor apropiación del tema de los derechos humanos, conceptual y existencialmente hablando, pues nótese cómo hoy en día se comprenden como realidades profundamente humanas, exigibles en el seno de la comunidad regional, nacional e internacionalmente hablando, en los ámbitos público y privado.

Así, tomamos base en la obligación que tiene el Estado de educar, promover y defender los derechos humanos, puesto que las autoridades deben, además de reconocerlos, ponerlos en práctica dentro de la sociedad, para que puedan desarrollarse y expresarse naturalmente, ya no como una realidad externa, sino como algo inherente a la cultura.

Con base en lo anterior, una definición conceptual sobre los derechos humanos habría de exaltar que cada vez más se amplía el conocimiento y la comprensión de que todos somos sujetos de derechos, que deben ser protegidos por los gobiernos, respetados y promovidos por toda persona, y vivenciados en la práctica cotidiana individual y colectiva, de tal manera que se genere una cultura sobre los mismos y una nueva sociedad fundamentada en los derechos y deberes individuales y colectivos, enalteciendo así el concepto mismo de la dignidad humana.

Pues bien, el hecho de que la sociedad ha llegado al consenso de que los derechos humanos son algo tan natural, tan propio del género humano, que siempre han existido y que históricamente se han ido configurando en luchas reivindicativas tanto prácticas como conceptuales, es una muestra más del logro de nuestros predecesores.

Ahora, la existencia de una definición clara y universal de los derechos humanos, nos hace comprender que estos son principios, atributos, cualidades y exigencias en sentido moral y político, que tienen todos los seres humanos por el hecho de serlo, por su propia naturaleza y dignidad. Derechos inherentes a cada persona que no solo nacen de una definición política, pero que necesitan ser consagrados y garantizados constitucionalmente por los Estados. 
Y es que tradicionalmente se han denominado de muy variadas formas: derechos humanos, derechos fundamentales, derechos del hombre, derechos públicos subjetivos, garantías individuales. Pluralismos que manifiestan la complejidad de la reflexión y del debate ideológico, filosófico, jurídico y político, histórico y actual, entre lo público y lo privado, lo ético y lo político.

Así, si buscamos una definición que logre sintetizar en forma más o menos ordenada todo lo indicado atrás, se diría que los derechos humanos son "un conjunto de facultades e instituciones, que en cada momento histórico, concretan las exigencias de la dignidad, la libertad y la igualdad humanas, las cuales deben ser reconocidas positivamente por los ordenamientos jurídicos a nivel nacional e internacional" (Pérez, 1995, p. 48).

Con todo, si son llamados "derechos humanos", es porque son del hombre, de la persona humana: el hombre es el único destinatario de estos derechos. Por ende, reclaman reconocimiento, respeto, tutela y promoción de parte de todos, $\mathrm{y}$ especialmente de los Estados. Estos derechos son inherentes a la persona humana; son universales, inalienables e imprescriptibles.

Dicho esto, es decir, establecido en forma rápida el concepto actual de los derechos humanos, podemos entrar a exponer sus características como veremos a continuación.

\subsection{Características}

El desarrollo conceptual histórico, filosófico y político de los derechos humanos, en palabras de Jiménez Zamora (2010), se sintetiza en seis características principales, a saber: a. Son universales: se adscriben a todos los seres humanos sin excepción, por cuanto todos los hombres participan de la misma e idéntica naturaleza e igualdad jurídica; b. Son inviolables: deben ser respetados por la sociedad, los individuos y el Estado, aunque este último tiene la responsabilidad primordial de su defensa y promoción; c. Son imprescriptibles: no se pierden, ni se adquieren con el paso del tiempo; d. Son inalienables: no son renunciables ni siquiera por decisión de su propio titular; e. Son indivisibles: la distinción entre clases de derechos es puramente teórica, ya que es la persona, sujeto de derechos, la que es atropellada cuando estos no se respetan; f. Son absolutos: puesto que se trata de exigencias morales tan fuertes que tienden a sobreponerse a cualquier otra pretensión moral ${ }^{6}$.

6 Téngase en cuenta que estas características han sido enunciadas y definidas de diversas formas similares, pero siempre manteniendo el mismo concepto, no solo en el ámbito doctrinal o legal, sino incluso jurisprudencial, por lo que las mismas constituyen una especie de noción dominante. 
Estas características constituyen la continua evolución y elaboración de los derechos humanos que, en suma, han llevado a que sean inherentes a nuestra legislación, no obstante, habrá de tenerse en cuenta que su desarrollo histórico y conceptual ha originado una forma de clasificación de los mismos en generaciones, como veremos a continuación.

\subsection{Clasificación de los derechos humanos por generaciones}

Al hablar de una clasificación de los derechos humanos por generaciones, se hace alusión tanto al orden constitucional como a las nuevas exigencias originadas por el progreso científico y tecnológico, la economía globalizada, el auge e influencia de las tecnologías de la información y las comunicaciones, entre otros, en la vida de los seres humanos y de los pueblos. Por lo tanto, se reconocen cuatro generaciones, a saber:

Una primera generación, conocida bajo el nombre de derechos civiles y políticos, tiene origen en la lucha contra el abuso de poder por parte de las autoridades. Imponen al Estado el deber de respetar los derechos y libertades de las personas.

Estos derechos se reconocen en el Pacto Internacional de Derechos Civiles y Políticos, creado en 1966, y se compone por los derechos a la vida, a la integridad física y moral, a la libertad personal, a la igualdad ante la ley, a la libertad de pensamiento, de conciencia y de religión, a la libertad de movimiento y tránsito, a la justicia, a la nacionalidad, a la participación política democrática y a la administración pública.

Una segunda generación, conocida bajo el nombre de derechos sociales y económicos, en la que se apela a la esperanza de los hombres de mejorar sus condiciones de vida dentro de la sociedad en lo económico y en lo cultural, en la medida en que otras valoraciones novedosas engrosan los conjuntos culturales de las diferentes sociedades.

Como dice Aguilar Cuevas (1988), estas ideas comienzan a plasmarse en las constituciones de México de 1917, y de la Alemania de Weimar en 1919, y su finalidad es promover mejores condiciones de vida para todas las personas en comunidad; se extienden a la esfera de responsabilidad del Estado, por medio de dos partes: la satisfacción de necesidades y la prestación de servicios. 
En esta forma, los derechos económicos, sociales y culturales son: la seguridad social, el trabajo, salario justo y equitativo, creación y afiliación a sindicatos, descanso, tiempo libre y recreación, salud, bienestar, alimentación, vivienda, servicios de salud, seguros de desempleo, enfermedad, invalidez, vejez, etc., maternidad y cultura, entre otros.

Una tercera generación, enfocada en los derechos de los pueblos, o derechos de solidaridad. Estos nacen de problemas y conflictos supranacionales como respuesta a la necesidad de cooperación entre las naciones, así como dentro de los distintos grupos que la integran.

Como dice Estrada López (2006), los derechos de tercera generación se refieren al derecho a la preservación del medioambiente, al derecho al desarrollo económico de todos los pueblos, al derecho a la paz, al derecho a la autodeterminación de los pueblos, al disfrute de los recursos naturales, patrimonio cultural y artístico, y al desarrollo digno de los pueblos indígenas y de las naciones de tercer mundo, entre otros.

Estos derechos de tercera generación son: al desarrollo integral del ser humano, al progreso y desarrollo económico y social de todos los pueblos, a la descolonización, a la prevención de todo tipo de discriminación, al mantenimiento de la paz y la seguridad internacionales, a la libre determinación de los pueblos -condición política, desarrollo económico, social y cultural-, y el derecho de los pueblos a ejercer soberanía plena sobre sus recursos naturales.

Finalmente, los derechos de cuarta generación, como lo dice Bustamante Donas (2010), constituyen la expansión del concepto a la ciudadanía digital, presentado por tres dimensiones: en primer lugar, como ampliación de la ciudadanía tradicional, enfatizado en los derechos relacionados con el libre acceso y uso de información, así como la exigencia de una interacción más simple y completa con las administraciones públicas mediante las redes telemáticas.

En segundo lugar, busca entender a la ciudadanía como una figura de lucha contra la exclusión digital, a través de la inclusión de colectivos marginales en el mercado de trabajo en una sociedad informática, mediante procedimientos deontológicamente obligatorios para el Estado, como lo son las políticas de profesionalización y capacitación.

Por último, una tercera dimensión enfocada en la elaboración de políticas de educación ciudadana, que generan una inteligencia colectiva que asegure una inserción autónoma a cada país en un mundo globalizado. 
Dicho lo anterior, no quiere afirmarse que los derechos de cuarta generación solo están enfocados en la ciudadanía digital, ya que, aunado a lo anterior, se encargan de promover el reconocimiento como sujetos sociales de nuevos actores y movimientos sociales.

Así, su explicación se basa en ubicar a la humanidad en una sola familia en búsqueda del bienestar global, la plena y total integración de la comunidad humana en el disfrute de la igualdad de derechos sin distinción de nacionalidad, orientación sexual, opción política, etc., reconociendo que son derechos supranacionales.

Así, expuestas estas cuatro generaciones ${ }^{7}$, encontramos la extensión que ha logrado el desarrollo del concepto de los derechos humanos, en su universalización, doctrina y política, como en sus implicaciones en las relaciones entre el Estado y los ciudadanos y, de estos entre sí, concepto puesto de manifiesto por Niño (1989), así:

El elenco de los derechos humanos es variado, incluyendo derechos relativos a la vida y la integridad física, libertades públicas y derechos de participación política; derechos de contenido económico, social y cultural. En un primer momento los derechos humanos se concibieron como ámbitos de protección del ser humano con respecto al poder del Estado y del gobierno, pero en la actualidad se considera que han de erguirse también frente a los particulares y sus acciones (p. 76).

Con todo, las disposiciones aquí señaladas rodean el concepto de los derechos humanos, razón por la cual habrían de tenerse todas reunidas para lograr un concepto más o menos completo.

Ahora bien, todo este conjunto conceptual no puede tener un sentido ajeno a los objetivos de esta investigación, pues, aunque más nos hemos enfocado en desarrollar una aproximación a los derechos humanos, lo cierto es que este extracto habrá de constituir la base sobre la cual estudiaremos una aproximación al derecho penitenciario.

7 Recientemente y ante la emergencia e influencia creciente de las tecnologías de la información y las comunicaciones - TIC- en la vida de las personas y de las comunidades, ha empezado a aflorar en el ambiente jurídico internacional, la idea de establecer una quinta generación de derechos humanos, tendientes a garantizar la protección de los ciudadanos y de los pueblos, frente a los impactos que estas tecnologías producen en la existencia humana. 


\section{Aproximaciones al derecho penitenciario}

La cárcel, en sus formas míticas o propiamente históricas, como encierro derivado de la venganza privada o de las distintas formas de legitimidad que el poder jurídico ha ido adquiriendo. El hecho de que la mayoría de un grupo humano tenga encerrado, estigmatizado y desacreditado a un conjunto reducido de su propia población hizo que ya desde los orígenes de la cárcel existieran debates y polémicas acerca de su existencia. Paralelamente, ya desde el principio de su devenir existencial han surgido múltiples teorías tan heterogéneas como dispares. Con acierto, Bueno Arús (2005) llega a proclamar "El Derecho penal ha estado en crisis desde siempre".

La teoría estructuralista trata de explicar a las "sociedades argumentando que son parecidas a un cuerpo humano y cada individuo o institución tiene una función dentro de ella, así como cada órgano tiene una función en el cuerpo" (Fernández, 2006). Según este pensamiento, si algo no funciona bien, la sociedad-cuerpo se enferma. Así, tratan de justificar el estado de las cosas en nombre de un supuesto buen funcionamiento de la sociedad, negando el conflicto social y la necesidad de cambios en la sociedad. Si existen desigualdades sociales y económicas es porque así debe ser.

Es en ese sentido, y no siguiendo las afirmaciones estructuralistas, que declaramos que la cárcel no cumple una función social. El sistema penitenciario de ninguna forma contribuye al libre desarrollo humano. Sin embargo, no negamos que el sistema penitenciario cumple funciones dentro de la sociedad; funciones que el poder le ha asignado desde su creación.

Lo que conocemos como prisión actualmente, empieza a formarse con la consolidación de la clase burguesa en Europa a finales del siglo XVII (Jaques, 1982). Con la consolidación de la burguesía y sus ideas de humanismo ilustrado se empieza a dejar atrás los actos públicos de castigo, los cuales fueron tachados de escenas repugnantes por los intelectuales de la época. Ya no se busca castigar el cuerpo a través del escarnio público, los castigos corporales o la ejecución, sino que se pretende castigar la mente del delincuente. Aunque las penas de privación de la libertad recaen directamente en el cuerpo, esta ya no está en la misma relación con el castigo, ahora el cuerpo es mas bien un intermediario, pues si se le encierra es para privar al individuo de algo más que su libertad. 
Así, el verdugo se vio sustituido paulatinamente por un sistema de castigo más acorde con las ideas de la modernidad burguesa y de la sociedad mercantilista que se empezaba a configurar. Una sociedad en la que se pretende que toda actividad humana sea vista en términos de mercancía. Tanto tienes, tanto vales. ¿Qué quieres decir o hacer y cuánto puedes pagar por ello?

Y por supuesto que el naciente sistema punitivo no estaría exento de esta lógica. ¿Qué delito cometiste, qué daño hiciste a la sociedad? Y en función de eso se determinará tu condena. Es lo que el derecho penal llama "teoría retributiva de la pena" (Fernández, 2006), es decir, pagar con tiempo en prisión el delito cometido, convirtiendo al tiempo en valor de cambio.

Otra característica de este sistema penal es la idea reeducadora del castigo, es decir, después de que hayas pagado tu condena, estás listo para volver a la sociedad, pues ya aprendiste tu lección, la cual es, si te portas mal, mereces un castigo.

Como vemos, al sistema penitenciario actual se le puede rastrear un origen, trabajo que Michel Foucalt desarrolló en su obra. De nosotros depende ponerle un fin. Sin embargo, la abolición del sistema penitenciario, con sus cárceles, leyes, jueces, policías y castigos nos plantea la incógnita de qué hacer en su lugar, ya que es claro que tanto en el orden nacional como internacional la prisión no ha sido un mecanismo de castigo efectivo para tratar de resocializar a la población carcelaria.

Para entender el concepto de cárcel y con relación al término de pena se debe tener en cuenta la definición de derecho penitenciario, según la cual este es una "rama o ciencia del derecho como parte integrante de la penología, que fue definida por FRANCIS LIEBER en el año 1838 como "rama de la ciencia penal que se ocupa del castigo del delincuente" (Fernández, 2006). La penología persigue, en consecuencia, el estudio de los diversos medios de represión y prevención directa del delito (penas y medidas de seguridad), de sus métodos de aplicación y de la actuación postpenitenciaria.

Ahora, centrándonos en el ámbito nacional, se ha visto un progreso significativo frente al sistema carcelario y penitenciario, ofreciendo mayor garantía el régimen actual, por cuanto se encuentra establecido bajo la Constitución Política de Colombia de 1991, la cual introduce la concepción de un Estado social de derecho, cuyo fin principal es la protección y el respeto a la dignidad humana, el trabajo y la solidaridad de las personas que integran el territorio. Concluyendo preliminarmente, si bien es cierto que Colombia cuenta con normas que regulan, protegen y preservan los derechos de las personas que se encuentran privadas de la libertad, y taxativamente 
podría inferirse que existe un sistema penitenciario garantista, en el diario vivir se evidencia la falta de políticas gubernamentales y mecanismos de protección que den lugar a un óptimo resultado en la aplicación del sistema, pues, de lo contrario, las personas que se encuentran privadas de la libertad no tendrían que acudir a la acción de tutela para garantizar el correcto cumplimiento de sus derechos.

Colombia se encuentra constituida dentro de un régimen de Estado social de derecho, por tanto el Estado colombiano debe propender a brindar a sus asociados las garantías necesarias para la protección de los derechos fundamentales reconocidos en la carta política (Contraloría Delegada, 2008), así como en tratados internacionales suscritos por Colombia, como es el caso del Pacto Internacional de Derechos Civiles y Políticos, la Convención Interamericana para Prevenir y Sancionar la Tortura, la Declaración Universal de los Derechos Humanos, entre otros. De este modo, Colombia está en el deber de brindar un sistema garantista fundado principalmente en el respeto a la dignidad humana, cuya función principal sea la resocialización y la rehabilitación de aquellas personas que se encuentran detenidas, mediante las instituciones encargadas de ello.

Por lo anterior, se busca dar respuesta al porqué aun cuando el Estado colombiano debe propender a brindar a sus asociados un estilo de vida digno, basado en la protección de los derechos, garantizando el cabal cumplimiento de los mismos, con fundamento en el artículo 1 de la Constitución Política el cual señala:

Colombia es un Estado social de derecho, organizado en forma de República unitaria, descentralizada, con autonomía de sus entidades territoriales, democrática, participativa y pluralista, fundada en el respeto de la dignidad humana, en el trabajo y la solidaridad de las personas que la integran y en la prevalencia del interés general. (Corte Constitucional, Sala de Revisión $\left.\mathrm{n}^{\circ} .4, \mathrm{~T}-213,2011\right)$

En 1837, bajo el Gobierno de José Ignacio de Márquez, se expidió el primer Código Penal en Colombia (INPEC, 2015), a partir del cual se reproducen por primera vez los principios rectores de la ciencia penal y se introduce la pena privativa de la libertad como sanción fundamental, que cumplió en este momento con dos funciones: colaborar con el proceso de formación del Estado nación que se desarrollaba en ese período de la historia y ser un elemento de la disciplina. Una de las partes del Código Penal fue el estatuto para las prisiones, el cual tenía como base la resocialización del delincuente. 
Las sucesivas normas carcelarias derogaron la legislación anterior y se preocuparon por, lo que el mismo INPEC definía como:

[...]mantener en buenas circunstancias a los presos, puesto que fueron cuidadosas con la selección y nombramiento del personal de vigilancia, buscaron que los presos tuvieran buen alojamiento, se organizaron los trabajos de tal forma que todos los detenidos se mantuvieran su tiempo ocupado para evitar la ociosidad. (INPEC, 2015)

Sistema Carcelario y Penitenciario actual en Colombia. En la actualidad, Colombia se rige bajo la Ley 65 de 1993, que es el actual Código Penitenciario y Carcelario, en el cual se estable el respeto a la dignidad humana de esta manera:

Artículo 5. En los establecimientos de reclusión prevalecerá el respeto a la dignidad humana, a las garantías constitucionales y a los derechos humanos universalmente reconocidos. Se prohíbe toda forma de violencia psíquica, física o moral. (Papacchini, 1994)

Así mismo, el artículo 9 prescribe las funciones y finalidad de la pena y de las medidas de seguridad, expresado en palabras de la Corte, así: "La pena tiene función protectora y preventiva, pero su fin fundamental es la resocialización. Las medidas de seguridad persiguen fines de curación, tutela y rehabilitación" (Corte Constitucional, Sala de Revisión n. ${ }^{\circ}$ 5, T-256, 2000). Esta norma es de gran relevancia para el objeto del presente estudio, por cuanto se está mencionando la finalidad de la pena, y es justamente este punto el que se está quebrantando e incumpliendo. Así mismo, se encuentra el artículo 10, referente a la finalidad del tratamiento penitenciario, el cual invoca:

El tratamiento penitenciario tiene la finalidad de alcanzar la resocialización del infractor de la ley penal, mediante el examen de su personalidad y a través de la disciplina, el trabajo, el estudio, la formación espiritual, la cultura, el deporte y la recreación, bajo un espíritu humano y solidario. (Ley 65, 1993, art. 10)

\section{La relación entre el sistema carcelario y los derechos humanos}

Tomando las aproximaciones expuestas frente a los derechos humanos y al derecho penitenciario, sobre la base de la realidad jurídica colombiana, podemos señalar que particularmente en el ámbito de la política criminal (originado por los continuos actos de excesiva violencia), existe la preocupación y ocupación, por parte de las 
autoridades gubernamentales, por instar a la sociedad para que también se vincule en la resolución de conflictos que no solo atañen al Gobierno, sino que, por el contrario, incluyen a la sociedad, surgiendo así la necesidad de que la comunidad también participe con sus propuestas.

Ahora bien, nosotros como miembros de esta (nueva) sociedad (participativa), desde nuestra trinchera, la academia, igualmente, pretendemos involucrarnos en esta problemática que padece nuestro país, por lo que del panorama crítico en materia de derechos humanos que se vive en las prisiones colombianas, nos llevan a concluir que, actualmente, la pena privativa de libertad sucumbe ante una serie de adversidades que, paulatinamente, se vienen incrementando y que inciden en el virtual fracaso carcelario.

En este sentido y como la misma Defensoría del Pueblo colombiana lo destaca (2004), podemos exaltar como factores negativos: a. La sobrepoblación; b. La violencia; c. Los motines; d. La corrupción; e. La opinión ciudadana; f. Las disconformidades y desconciertos que existen en el interior de la institución, por parte de quienes se encuentran recluidos; g. El rol que desempeñan los medios de comunicación, mostrando la realidad de las prisiones nacionales (deficiencias), sin que a la fecha, se haya concienciado plenamente a los poderes públicos de la necesidad de una norma eficiente que desarrolle una política criminal efectiva.

Es por lo anterior que hoy en día en el ámbito punitivo nacional existe un distanciamiento entre la realidad y la norma, lo que redunda en la ineficacia de la prisión. Pues bien, tengamos en cuenta que la eficiencia de un sistema penitenciario se ratifica "con el respeto a los Derechos Humanos de los internos, los bajos índices de reincidencia, de corrupción y de quebrantamientos de permisos de salida" (Defensoría del Pueblo, 2004), situación que, por supuesto, debería darse.

En esta forma, como hemos indicado, debemos proponer alternativas (jurídicas), que permitan potenciar, por un lado, la efectiva protección de los derechos humanos de los internos $\mathrm{y}$, por otro, la consecución del fin primario que impregna a las instituciones penitenciarias del país, que no es otro que el relativo a la reinserción social, con independencia de que se alcancen los fines secundarios, como la retención y custodia de los detenidos presos y penado, así como la asistencia a internos y liberados (objetivos que deben ser garantizados por todo Estado social de derecho, como presumimos, es el caso del Estado colombiano).

Siguiendo esta línea, en lo ateniente al ámbito penitenciario nacional, podemos señalar que, en la mayoría de los casos, la defensa de los derechos de los reclusos 
sucumbe ante los actos de las autoridades penitenciarias, toda vez que se carece de los institutos adecuados para la salvaguarda de los mismos; es decir, "se deja a los internos en un completo abandono" (Fernández, 2002), olvidándose del mencionado fin primario de la prisión colombiana, la reinserción social, que debe aplicarse a ellos.

Además, debemos mencionar que

pese a las declaraciones normativas que señalan que a los reclusos solo se les ha de privar de su libertad, todos y cada uno de sus derechos fundamentales (a la vida, a la salud y a la integridad física y psíquica, a la defensa, al trabajo remunerado, al respeto de su vida privada, al secreto de su correspondencia, etc.) se encuentran devalados en comparación con la tutela que poseen esos mismos derechos cuando los mismos se refieren a quienes viven en libertad. (Baratta, 2004, p. 351).

Estas circunstancias que se padecen en el interior de las prisión (abandono y devaluación de derechos de los penados), han motivado a algún sector de la doctrina penitenciaria nacional por considerarla como el lugar en el que, por antonomasia, se violan cotidianamente los derechos humanos, convirtiéndose su disfrute, en un lejano anhelo más que una realidad.

Ante este panorama, entendemos que es momento de actuar, dejar ser simples espectadores, para convertirnos en actores de una humanista política carcelaria nacional; por tanto, debemos pugnar porque se potencie la protección de los derechos humanos de los reclusos, pues estos continúan siendo "titulares de derechos (y obligaciones)", (Corte Constitucional, sent. T-077, 2013), con excepción de que les sean limitados los derechos que expresamente se señalen en fallo condenatorio, así como del contenido de la sentencia.

Ahora bien, dentro del catálogo de prerrogativas que deben observarse en favor de los cautivos encontramos: "a) Derechos como persona; b) Derechos como ciudadano; c) Derechos como interno” (Martínez, 1995).

Hacia la dignificación de los reclusos en Colombia, se debe erigir la política criminal en la actualidad como un ente social, democrático y de derecho, consecuentemente justo; entonces, el Estado debe configurarse como el garante 
de los derechos humanos de los miembros que lo integran. Esto significa que "las autoridades gubernamentales deben instrumentar políticas públicas" (Fernández, 2002), dirigidas a impulsar el reconocimiento y protección de los derechos humanos de los hombres en libertad, así como de aquellos que se encuentran expurgando una pena de prisión.

Ahora bien, consideramos que en Colombia existe una desatención a la sociedad carcelaria y su personal penitenciario. Surge aquí, por una parte, la demanda social y, por otra, la necesidad estatal por instrumentar políticas que, en armonía con los principios fundamentales penitenciarios y constitucionales, coadyuven a garantizar los mencionados "Derechos Humanos de los reclusos" (Organización de las Naciones Unidas, 2005), para ofertar las instituciones penitenciarias necesarias que, en forma concatenada, contribuirán al exitoso proceso de reinserción social de los penados, toda vez que la concepción resocializadora de la prisión obliga a entender la ejecución en un proceso de recuperación del penado.

Así pues, el gran desafío para el Sistema Penitenciario Colombiano radica en dignificar la estancia prisional. Debe resaltarse que de manera reiterada por parte del Estado colombiano se ha indicado su incapacidad económica y operativa para dar cumplimento oportuno y protección a los derechos fundamentales de las personas que se encuentran privadas de la libertad y quienes están bajo su custodia, argumentando serios problemas presupuestales y de infraestructura. Argumentaciones que no pueden ser de recibo dentro de una sociedad moderna, la cual busca desarrollarse como una colectividad garantista de las prerrogativas constitucionales y legales que ella misma ha creado para su convivencia, siendo inaceptable que se trate de forma diferenciada a quienes, infortunadamente, han cometido actos delictivos, los cuales merecen todo el reproche de la sociedad, pero de la misma forma toda la protección constitucional necesaria.

Se podría indicar que una de las causas por las cuales se presenta el hacinamiento en nuestros centros carcelarios es la grave crisis que afronta el Sistema Penal en Colombia, ya que en "menos de quince años se ha modificado el estatuto procesal penal en una docena de veces, generando con ello no solo inestabilidad jurídica" (INPEC, 2015), sino también un giro total en la política criminal del Gobierno nacional de turno, que desde su punto de percepción y dependiendo el momento histórico que se enfrente, ha determinado penalizar algunas conductas o incluso aumentar la pena a otras, con lo cual se ha generado una especie de "embotellamiento penitenciario", es decir, ingresan muchos individuos a las cárceles, pero emigran pocos de ellas. 
La dignidad del preso se ve limitada e incluso en la mayoría de los casos pisoteada y vulnerada en gran parte de las prisiones o cárceles colombianas, no solo por la infraestructura de las mismas o por los problemas en el sistema judicial, sino también por los funcionarios que laboran en ellas, pues algunos se han visto envueltos en escándalos de corrupción, porque abusan de su posición dominante y rango para exigir el pago de dádivas y coimas por prestar el servicio carcelario de forma adecuada.

Pareciera pues que dentro de las cárceles colombianas los derechos fundamentales, principios y normas rectoras (propias del Estado social de derecho), no existieran, siendo por el contrario, el dinero el único medio de resguardo o de protección de la dignidad humana del penado, el cual se encuentra en una jungla de concreto y de barrotes de acero.

La dignidad humana, como principio fundante del Estado social de derecho, implica que todas las instituciones deben estructurarse, regirse y consolidarse de acuerdo con ella, así como también que el marco normativo sea interpretado y postulado con base en esta misma. Por eso, la Corte Constitucional y el poder legislativo han tomado una serie de medidas para proteger al reo y ubicarlo en una situación de especial protección, con el fin de evitar que sus derechos fundamentales sean escarnecidos. Míseramente, todo lo anterior se desdibuja evidenciando la realidad de las prisiones colombianas, las cuales se enmarcan dentro de un panorama pavoroso, donde la dignidad es valorada de acuerdo al dinero que se tenga, donde el hacinamiento, la sobrepoblación, la corrupción de los funcionarios y la violencia interna, son algunos de los problemas que afronta la población carcelaria, que en la mayoría de los casos ni siquiera han sido declarados responsables penalmente.

Resulta, entonces, que la función resocializadora de la cárcel no se evidencia ni se cumple a cabalidad en razón de los evidentes problemas citados en precedencia, desencadenando con esto problemas mucho más graves no solo en los internos, sino también en su entorno social, afectivo y familiar, por ende, es preciso explorar diferentes "alternativas para la descongestión de dichos centros carcelarios, como lo son las multas o trabajos comunitarios" (Defensoría del Pueblo, 2004), con el fin de mitigar las vulneraciones que sufren los reos dentro de las prisiones colombianas.

Finalmente, es importante reforzar la asistencia pospenitenciaria, pues todo lo conseguido durante la fase procedimental resocializadora, deviene inútil si no se lleva a cabo un efectivo seguimiento y apoyo a quien ha salido libre, una vez que se integra a la sociedad, acompañado de una política criminal alternativa, cuyo principal fundamento sea el respeto absoluto por la dignidad humana, donde la 
disposición de medios sociales para la prevención, lo más efectiva posible, de los fenómenos criminales y en último término por el recurso al derecho penal, siempre en el marco de los derechos humanos.

Los centros penitenciarios y carcelarios nacionales atraviesan por indiscutibles problemas que requieren de una solución rápida y equilibrada. Las dificultades no solo afectan el servicio de tal sistema, sino que atentan directamente contra los derechos fundamentales y dignidad humana de los reos colombianos, a pesar de encontrarse en un estado especial de sujeción y de ser la dignidad humana una característica propia del Estado social de derecho y principio fundante del mismo.

De lo expuesto, se tiene entonces que la función sancionatoria de la conducta penal en centro carcelario se agrava con las ínfimas e inhumanas condiciones de vida que tienen los internos en todas las cárceles del territorio nacional, las cuales vulneran ostensiblemente los derechos fundamentales de los apresados, así como tampoco logran el fin para el cual fue creada; por ende, el Gobierno nacional es llamado para velar por la "dignidad humana del interno" (Corte Constitucional, sent. T-266, 2013).

\section{Los derechos humanos como límite al sistema carcelario en Colombia}

Indudablemente, los centros penitenciarios y carcelarios del país tienen problemas que requieren de una solución pronta y equilibrada, algunos de ellos son el hacinamiento, la sobrepoblación, la corrupción por parte de directivos y funcionarios del INPEC, la violencia, entre otros. Estos problemas no solo afectan el servicio de tal sistema, sino que atentan directamente contra los derechos fundamentales y la dignidad humana de los penados, a pesar de encontrarse en un estado especial de detención y de ser la dignidad humana una característica propia y pilar esencial del Estado social de derecho.

Los derechos humanos y en especial la dignidad humana son principios inseparables de todo individuo perteneciente a este compuesto social, aunde aquellos que con su proceder -doloso o no-, quebrantaron el ordenamiento jurídico y se encuentran confinados en centros penitenciarios, razón por la cual, en aras de salvaguardar sus garantías fundamentales, establecer un marco normativo y reglamentar la especial relación existente, fue creado por el legislador con el Código Penitenciario y Carcelario, a fin de atender las necesidades básicas de los reos, ofrecer garantías jurídicas y sociales, con base en la relación especial sujeción, toda vez que al configurarse la privación de la libertad, algunas de sus prerrogativas constitucionales dependen directamente del aparato estatal. 
A pesar de lo anterior, dentro de las prisiones se presentan diferentes problemas que afectan de manera directa o indirecta la interacción del individuo en el centro carcelario, situaciones que con el presente artículo se pretenderán avizorar, a fin de establecer la frontera entre derechos humanos y el ámbito jurídico penitenciario.

Para conocer las verdaderas condiciones de dicho grupo poblacional, se deben establecer diferentes aspectos, como el político, social, cultural, religioso, institucional, jurídico y económico. De ahí la falta de oportunidades de la población penitenciaria para lograr su proceso de resocialización, las necesidades de aquellos y el inminente colapso de las cárceles, si no se implementan medidas de descongestión o construcción de nuevos establecimientos que permitan que los procesados reciban un óptimo tratamiento.

La evolución de la humanidad ha traído consigo un sinnúmero de cambios, entre ellos, la concepción y visión de la cárcel, la cual fue creada para cumplir dos finalidades desde esta nueva perspectiva: "una función retributiva y otra resocializadora" (Fernández, 2002, p. 52). En cuanto a la primera, el castigo consiste simplemente en la privación de la libertad, y respecto a la segunda, se hace preciso que el reo tenga la posibilidad de que al terminar de cumplir su pena pueda reinsertarse en la sociedad, para lo cual, durante el tiempo de la ejecución de la pena en el centro penitenciario realice actividades que mejoren su comportamiento social e intelectual, tales como estudiar, trabajar y enseñar. Es así como bajo la concepción del Estado social de derecho, "ningún sistema penitenciario debe estar orientado solamente al castigo" (Corte Constitucional, sent. T-077, 2013), sino también a lograr la resocialización del recluso y que en el momento de recobrar su libertad cuente con las herramientas fundamentales para un correcto desenvolvimiento en la misma sociedad, iniciando incluso un nuevo proyecto de vida que aporte al desarrollo de su comunidad.

Es así como en el Estado social de derecho, la sanción no debe implicar la imposición de otro tipo de aflicción o sufrimiento, diferente al derivado directamente de la pena; cada limitación de los derechos del penado debe estar soportada y justificada como una medida necesaria y proporcionada para lograr su resocialización o para reafirmar el goce de sus derechos, previo consentimiento y acción positiva del interno, como pilar esencial de ayuda a la sociedad y al mismo recluso, buscando afianzar principios y valores para lograr un verdadero cambio en su interacción con la comunidad.

Resulta que un gran porcentaje del marco normativo nacional se vio obsoleto por causa del cambio constitucional que se dio a principios de la última década del siglo XX, exteriorizándose la insuficiencia de promulgar un nuevo ordenamiento jurídico aplicable a las exigencias constitucionales mínimas. Como consecuencia 
de lo anterior, y en aras de iniciar una regulación del tema carcelario y penitenciario, se expidió una serie de normas, tales como el Estatuto de las Penas, el Código de Procedimiento Penal, el Código Penitenciario y Carcelario, entre otras.

Justamente, se presume que dentro del Estado social de derecho no estaría en peligro y mucho menos que se vulneraría la dignidad humana como principio fundante del mismo, pero la realidad es otra y refleja lo contrario, ejemplo de ello es la situación en la que se encuentran los reclusos en Colombia, pues basta dar una rápida mirada a las condiciones actuales de reclusión-celdas aglutinadas de personas, condiciones sanitarias peligrosas, alimentación inadecuada-, para darse cuenta de que ponen en riesgo la salud y de que son una clara vulneración a los derechos humanos de la población dentro de las prisiones.

A pesar de ser la dignidad humana, en teoría, el pilar de todas las instituciones del Estado, en el interior de la mayoría de los sitios de reclusión, en muchos casos esta es mancillada, menospreciada e incluso transgredida. Esto se debe a diferentes aspectos e intereses internos y externos de las prisiones, algunos de ellos, grosso modo, pueden ser el hacinamiento, el cual supera el porcentaje normal de habitabilidad de la planta física de las penitenciarías, la corrupción, dificultades entre presos y guardias del INPEC, entre otros que van erosionando el sistema penal actual.

Además, es de advertir que conforme a jurisprudencia de la Corte Constitucional, el reo, precisamente por su condición, "se encuentra en una relación especial de sujeción con el Estado" (sent. T-077, 2013), lo cual debería transformarse en una protección especial de sus derechos fundamentales y, específicamente, de la calidad de vida de quien se encuentra privado de la libertad, ya sea en calidad de enjuiciado o de condenado.

Teniendo en cuenta lo expuesto, la dignidad humana, como derecho fundamental, lleva consigo la prohibición expresa de su limitación y el Estado está en la obligación de satisfacer las necesidades mínimas vitales de la persona privada de la libertad, como lo son la alimentación, la habitación, el suministro de útiles de aseo, la prestación de servicio de salud, etc., dado que quien se halle internado en un centro de reclusión, justamente por su especial circunstancia, está en la imposibilidad de procurarse en forma autónoma tales beneficios. Por ende, una suspensión o limitación de los derechos fundamentales que no esté legitimada en estos objetivos, que sea innecesaria o desproporcionada, resulta una sanción adicional y excesiva no autorizada por la Constitución, constituyéndose en una violación directa de los derechos fundamentales del reo. 
La Corte Constitucional ha determinado que los derechos fundamentales de los reclusos pueden clasificarse en tres grupos:

(i) aquellos derechos suspendidos como consecuencia lógica y directa de la pena impuesta, lo cual se justifica constitucional y legalmente por los fines de la sanción penal. Dentro de este grupo encontramos derechos como la libre locomoción, y los derechos políticos como el derecho al voto. (ii) los derechos intocables conformados por los derechos fundamentales de la persona privada de la libertad que se encuentran intactos, pues aquellos derivan directamente de la dignidad del ser humano, son ejemplo de estos: los derechos a la vida y el derecho al debido proceso, y por último, (iii) se encuentran los derechos restringidos o limitados por la especial sujeción del interno al Estado y tienen sentido porque con ello se pretende contribuir al proceso de resocialización del condenado y garantizar la disciplina, seguridad y salubridad en las cárceles. Encontramos limitados los derechos a la intimidad personal y familiar, de reunión, de asociación, libre desarrollo de la personalidad, libertad de expresión, al trabajo y a la educación. Respecto de los derechos fundamentales de los reclusos que admiten restricción, es importante tener en cuenta que su limitación es constitucionalmente válida en la medida en que se ajuste a los principios de razonabilidad y proporcionalidad. (Corte Constitucional, sent. T-815 de 2013).

Es tal la importancia, que la garantía de los derechos humanos está cimentada en la consideración de la dignidad humana como esencia de la naturaleza del hombre. Pues resulta claro que en su trasegar histórico, la dignidad, como exigencia moral, se ha positivado a través de la creación de los derechos fundamentales, faro en la aplicación de medidas y garantía de derechos. Además, resulta claro en el marco de la normatividad nacional, que para la aplicación de este principio debe tenerse en cuenta el artículo 13 de la norma constitucional, pues dados los criterios de igualdad, su garantía debe extender a todas las personas sin ninguna distinción, incluso aquellas que por diversas circunstancias se encuentran privadas de la libertad. Bien ha dicho la Corte en diversos pronunciamientos:

La persona recluida en un centro carcelario mantiene su dignidad humana, como lo reconoce el artículo $5^{\circ}$ constitucional al expresar que "el Estado reconoce, sin discriminación alguna, la primacía de los derechos inalienables de la persona". El hecho de la reclusión no implica la pérdida de 
su condición de ser humano, porque, como lo indica la función y finalidad de la pena, esta se ejecuta para la protección de la sociedad, la prevención del delito y, principalmente, como un proceso de resocialización del sujeto responsable del hecho punible. (Corte Constitucional, sent. T-065, 1995).

Por otra parte, de conformidad con el artículo 93 Superior, el mencionado catálogo de derechos fundamentales de los reclusos debe ser interpretado a la luz de los tratados internacionales ratificados por Colombia. La Declaración de los Derechos Humanos de 1948 fue uno de los primeros tratados que prohibió el trato cruel e inhumano, dispuso que nadie debe ser sometido a torturas ni a penas o tratos crueles, inhumanos o degradantes. De igual forma, el Pacto Internacional de Derechos Civiles y Políticos de 1966 reza en su artículo 10.3, "El régimen penitenciario consistirá en un tratamiento cuya finalidad esencial será la reforma y la readaptación social de los penados (...)".

Con base en los razonamientos expuestos y en la orientación de la Constitución Política de Colombia, se estableció en el ordenamiento jurídico interno un estatuto de carácter normativo, dirigido no solo a la prevención, sino a la protección de los derechos fundamentales de los internos en nuestro país, mediante la consolidación de ciertos deberes positivos en cabeza del Estado, conforme a los cuales, en los establecimientos de reclusión siempre deberá prevalecer el respeto a la dignidad humana, a las garantías constitucionales y a los derechos humanos que han sido reconocidos de forma universal. Por esta razón, toda persona a quien se le atribuya la comisión de un hecho punible, tiene derecho a ser tratada con el respeto debido a la dignidad inherente al ser humano, sin distinción del cometimiento de la acción delictual, siendo esta la causa que motiva también la idea de que toda persona privada de la libertad deberá tener derecho a recibir en el lugar de reclusión un tratamiento acorde con el respeto de los derechos humanos, como los de no ser víctima de tratos degradantes e inhumanos.

Llegando a la norma nacional, el artículo 5 de la Ley 65 de 1993, modificada por la Ley 1709 de 2014 en su artículo 4, establece que: "Artículo 5. Respeto a la dignidad humana. En los establecimientos de reclusión prevalecerá el respeto a la dignidad humana, a las garantías constitucionales y a los Derechos Humanos universalmente reconocidos. Se prohíbe toda forma de violencia psíquica, física o moral. Las restricciones impuestas a las personas privadas de la libertad estarán limitadas a un estricto criterio de necesidad y deben ser proporcionales a los objetivos legítimos para los que se han impuesto. La carencia de recursos no podrá justificar que las condiciones de reclusión vulneren los derechos fundamentales de las personas privadas de la libertad". 
Sirve todo lo anterior para auscultar acerca del cumplimiento de cada una de las prerrogativas que deben tener las personas privadas de la libertad por el tiempo en que se encuentren recluidas en dichos centros penitenciarios, y no se necesitan mayores elucubraciones para establecer con claridad que, en efecto, no se cumple a cabalidad la norma citada, no solo por la carencia de sitios adecuados para la correcta reclusión del personal penitenciario, sino también por la falta de dotación de implementos de aseo, educación, deporte y cultura, que hacen que se obstruya de manera tajante el proceso de resocialización de la persona privada de la libertad.

\section{Conclusiones}

La dignidad humana, como principio fundante del Estado social de derecho, implica que todas las instituciones deben regirse y consolidarse de acuerdo con ella, así como también que el marco normativo sea interpretado y postulado con base en esta misma. Es así como la Corte Constitucional y el poder legislativo han tomado una serie de medidas para proteger al reo y ubicarlo en una situación de especial protección, con el fin de evitar que sus derechos fundamentales sean escarnecidos.

Sin embargo, en los últimos años la inquietud por los derechos humanos se puede constatar en la práctica jurídica y política del país. Ha sido una verdadera conquista de las tres últimas décadas el reconocimiento universal que todos los miembros de la familia humana, sin excepción alguna, deben disfrutar de un mínimo de derechos y libertades que les permita vivir con la dignidad de seres humanos. Al adentrarnos en la evolución de los derechos humanos se observa, en primer lugar, un esfuerzo constante y ascendente de la comunidad internacional para hacer germinar un nuevo orden jurídico que asegure suficiente protección a los individuos y grupos humanos alejados del poder frente a la arbitrariedad y opresión del Estado. La defensa y la promoción de los derechos humanos no es solo en sí mismo un derecho fundamental, es también por mandato de la Constitución Política y un deber de la persona y de la comunidad; por lo tanto, el Estado tiene la obligación de amparar esos derechos y a quienes los defienden. Con razón se advierte que la defensa de los derechos humanos es una tarea común de todos los integrantes de la familia humana y no una actividad reservada únicamente a quienes participan en organizaciones no gubernamentales. Defender los derechos humanos es, al mismo tiempo, un derecho y un deber personal y comunitario.

Todo lo anterior queda en segundo lugar al observar la realidad de las prisiones del país, las cuales se enmarcan dentro de un horizonte aterrador, donde la dignidad es valorada de acuerdo con el dinero que se tenga, donde el hacinamiento, la 
sobrepoblación, la corrupción de los funcionarios y la violencia interna, son algunos de los problemas que afrontan los recursos, quienes, en la mayoría de los casos, ni siquiera han sido declarados responsables penalmente.

Por otra parte, la obsoleta infraestructura que presentan algunos centros carcelarios en el ámbito nacional, evidencia la grave situación que afrontan a diario las personas privadas de la libertad, ya que la estructura de las celdas, el tamaño y su ubicación, no responden a la necesidades de la población carcelaria, siendo este un incumplimiento propio del Estado, toda vez que es deber de este preservar los derechos fundamentales de los reclusos, que no resultan restringidos o suspendidos como consecuencia de su situación penal, tales como la dignidad, la salud, la alimentación, siendo tales circunstancias las que impiden que el Estado cumpla su función resocializadora adecuadamente. Con esta situación, la administración de los centros penitenciarios y el Estado en particular, en algunos casos ultrajan los derechos humanos de los internos, específicamente la dignidad humana.

Debe resaltarse que de manera reiterada se ha indicado la incapacidad económica y operativa por parte del Estado colombiano para dar cumplimento oportuno y protección a los derechos fundamentales de las personas que se encuentran privadas de la libertad y quienes están bajo su custodia, argumentando serios problemas presupuestales y de infraestructura, pero dentro de una sociedad moderna, la cual busca desarrollarse como una colectividad garantista de las prerrogativas constitucionales y legales que ella misma ha creado para su convivencia, siendo inaceptable que se trate de forma diferenciada a quienes por infortunio han cometido actos delictivos, los cuales merecen todo el reproche de la sociedad, pero, de la misma forma, toda la protección constitucional necesaria; y se recalca, independientemente de recursos materiales disponibles por parte del Estado para su salvaguarda.

Se puede afirmar que la crisis que afronta el Sistema Penal en Colombia es muy grave, ya que en menos de quince años se ha modificado el estatuto procesal penal una docena de veces, generando con ello no solo inestabilidad jurídica, sino también un giro total en la política criminal del Gobierno nacional de turno, que desde su punto de percepción y dependiendo del momento histórico que se enfrente, ha determinado penalizar algunas conductas o incluso aumentar la pena a otras, con lo cual se ha ocasionado una especie de "embotellamiento penitenciario", es decir, ingresan muchos individuos a las cárceles pero emigran pocos de ellas. 
De lo expuesto en este artículo de investigación, se observa que la función sancionatoria de la conducta penal en centro carcelario se empeora con las inferiores e inhumanas condiciones de vida que tienen los internos en todas las cárceles del territorio nacional, que vulneran ostensiblemente los derechos humanos de los apresados, especialmente su dignidad humana.

\section{Referencias}

Aguilar, M. (1998). Las tres generaciones de los derechos humanos. Derechos humanos. Órgano Informativo de la Comisión de Derechos Humanos del Estado de México, 30, 93-102.

Asamblea General de Naciones Unidas (1948, 10 de dic.). Declaración Universal de los Derechos Humanos. Resolución 217 A (III), de 10 de diciembre de 1948 .

Asamblea General de Naciones Unidas (1966, 16 de dic.). Pacto Internacional de Derechos Civiles y Políticos. Resolución 2200 A (XXI), del 16 de diciembre de 1966.

Baratta, A. (2004). Derechos humanos: entre violencia estructural y violencia penal. En Criminología y sistema penal. Compilación in memoriam. Montevideo: B de F.

Bustamante, J. (2010). La cuarta generación de derechos humanos en las redes digitales. Telos. Cuadernos de Comunicación e Innovación, 1, 1-10.

Código Penal colombiano. (2000, 24 de julio). Ley 599 de 2000. Diario Oficial, (44.097).

Código de Procedimiento Penal colombiano. (2004, 1 de sep.). Ley 906 de 2004. Diario Oficial, (45.658).

Constitución Política de Colombia. (1991, 10 de oct.). Texto de la Constitución. Gaceta Constitucional, (127).

Defensoría del Pueblo (2004). Análisis sobre el actual hacinamiento carcelario y penitenciario en Colombia. Bogotá: Defensoría del Pueblo. 
Estrada, E. (2006). Derechos de tercera generación. Podium Notarial, 34, 249-257.

Fernández, J. (2002). Derecho penal liberal de hoy. Bogotá: Gustavo Ibáñez.

Instituto Nacional Penitenciario y Carcelario -INPEC- (2015, feb.). Informe estadístico. Bogotá: Oficina Asesora de Planeación, Grupo Estadística, INPEC.

Jiménez, V. (2010). Derechos humanos y colectivos vulnerables: un reto para la Iglesia. Corintios XIII, 137-138, 55-80.

Martínez, M. (1995). Estado de derecho y política criminal. Bogotá: Gustavo Ibáñez.

Niño, C. (1989). Ética y derechos humanos. Barcelona: Ariel.

Organización de Naciones Unidas. (2005). Los derechos humanos y las prisiones. Manual de bolsillo de normas internacionales de derechos humanos para funcionarios de instituciones penitenciarias. Recuperado de: http://www. ohchr.org/Documents/Publications/training11Add3sp.pdf.

Papacchini, A. (1994). Filosofia y derechos humanos. Santiago de Cali: Facultad de Humanidades y Democracia.

Pérez, A. (1995). Derechos humanos, estado de derecho y constitución. Madrid: Tecnos.

Real Academia Española (2014). Diccionario de la lengua española (23 ed.). Madrid: Real Academia Española.

Zambrano, L. S. (2013). Derechos humanos como límite franqueable del sistema penitenciario en Colombia. Periodo: 2000-2012. Tesis de maestría no publicada. Universidad Pedagógica y Tecnológica de Colombia, Tunja, Colombia. 
